\title{
RANCANG BANGUN ALAT PEMISAH BUAH TOMAT BERDASARKAN WARNA MENGGUNAKAN SENSOR CAHAYA
}

\author{
Bangun Samudra ${ }^{1}$ \\ Program Studi Teknik Elektro, Fakultas Teknik, Universitas Panca Marga \\ Email: bangunsamudra123@gmail.com \\ Ira Aprilia ${ }^{1}$ \\ Program Studi Teknik Elektro, Fakultas Teknik, Universitas Panca Marga \\ Email: ira.aprilia11@upm.ac.id \\ Misdiyanto ${ }^{1}$ \\ Program Studi Teknik Elektro, Fakultas Teknik, Universitas Panca Marga \\ Email: misdie@upm.ac.id
}

\begin{abstract}
The need for basic commodities in Indonesia increases every year. Especially for the needs of tomatoes, which are consumed by most of Indonesian people every day. Tomato has several uses based on its color, such as the raw (green) and half-ripe (yellow) tomatoes for cooking spices, while the ripe (red) tomatoes are used for making beverage. On the other hand, most of farmers still use manual methods to sort the tomatoes, from picking the tomatoes until sorting them by color. As a result, to provide the market's demands, farmers experience several obstacles, such as the large amount of labor required and the farmers' saturation during the tedious sorting process. Therefore, from this problem, it is needed a tool that can sort tomatoes by color automatically using the TCS3200 sensor as a color detector and Arduino as the control center for the tool. Using these tools, farmers can work faster and reduce boredom due to a tedious process. The results of the study were carried out through 10 times testing that showed 7 times success and 3 times errors. From these tests it can be concluded that the accuracy rate of the tool is $70 \%$.
\end{abstract}

Keywords : Arduino, Sorting, TCS3200 sensor.

ABSTRAK: Kebutuhan bahan pokok di Indonesia semakin meningkat setiap tahunnya. Khususnya untuk kebutuhan buah tomat yang setiap hari dibutuhkan hampir semua masyarakat Indonesia. Buah tomat memiliki beberapa kegunaan jika dilihat dari warnanya, untuk buah tomat yang belum matang (hijau) dan yang setengah matang (kuning) untuk campuran bumbu masak sedangkan untuk buah tomat yang matang (merah) digunakan untuk membuat jus. Tapi sebagian besar petani masih menggunakan cara manual untuk memilah buah tomat tersebut. Mulai dari memetik tomat terlebih dahulu kemudian memilahnya berdasarkan warnanya. Akibatnya untuk memenuhi jumlah kebutuhan yang ada, petani mengalami beberapa kendala. Oleh karena itu, dari masalah tersebut dibuatkan alat yang dapat mensortir buah tomat berdasarkan warna secara otomatis menggunakan sensor TCS3200 sebagai pendeteksi warna dan arduino sebagai pusat pengendali alat tersebut. Dengan adanya alat ini petani dapat melakukan pekerjaan persortiran lebih cepat dan dapat mengurangi kejenuhan karena proses yang membosankan. Hasil dari penelitian dilakukan 10x pengujian terdapat $7 \mathrm{x}$ berhasil dan $3 \mathrm{x}$ error. Dari pengujian tersebut dapat disimulkan bahwa tingkat akurasi alat sebesar $70 \%$.

Kata Kunci : Arduino, penyortiran, sensor TCS3200

\section{PENDAHULUAN}

$\mathrm{M}$ eningkatnya produksi pangan di negara Indonesia khususnya dibidang pertanian, maka diperlukan produksi berskala besar untuk memenuhi peningkatan kebutuhan bahan pangan yang sedang terjadi. Oleh karena itu, dibutuhkan teknologi yang mudah, cepat dan efisien untuk membantu petani untuk terus memproduksi hasil panennya secara tepat. Khususnya untuk buah tomat, seperti kita tahu bahwasanya buah tomat adalah bahan pangan yang sering kali di cari oleh sebagian besar masyarakat untuk diolah menjadi campuran dalam proses memasak atau untuk hal - hal lainnya. Dan buah tomat memiliki kegunaan sesuai tingkat warnanya, yaitu untuk tomat yang hijau atau kuning biasanya dibuat untuk bumbu masak, sedangkan buah tomat yang sudah merah digunakan untuk membuat jus.

Seperti yang sering penulis jumpai, beberapa petani tomat melakukan hasil panen dengan cara memilah - milah buah tomat yang merah, kuning dan hijau secara manual atau menggunakan beberapa orang untuk melakukan aktifitas tersebut. Pastinya cukup merepotkan selain biaya yang harus dikeluarkan cukup besar, memerlukan tenaga kerja yang lumayan banyak dan waktu yang diperlukanpun cukup lama. Hasilnya terkadang masih sering terjadi kegagalan dalam proses memilah atau sortir buah tomat tersebut. Memang pekerjaan itu cukup menghabiskan banyak waktu dan menguras tenaga mungkin karena pekerjaan yang sangat membosankan sehingga sering terjadi kesalahan dan hasilnya tidak sesuai yang diinginkan.

Oleh karena itu, untuk penyortiran tomat secara beragam dibutuhkan alat yang dapat memilah buah tomat otomatis berdasarkan warna dengan menggunakan sensor pendeteksi warna seperti TCS3200 dan

\footnotetext{
${ }^{1}$ Program Studi Teknik Elektro, Fakultas Teknik, Universitas Panca Marga
} 
ditambah menggunakan Arduino Uno sebagai pusat pemrosesannya. Sehingga dapat menghasilkan pengelompokkan tomat lebih akurat dan dapat menghemat biaya, waktu dan tenaga.

\section{Tomat}

\section{KAJIAN PUSTAKA}

Tomat adalah tanaman yang memiliki dua jenis akar yaitu berakar serabut dan berakar tunggang. Akar serabut selalu tumbuh ke arah samping dan akar tunggang dari tanaman tomat tumbuh menembus kedalam tanah. Dengan kondisi tersebut lebih baik tanaman ini ditanam pada tanah yang gembur dan banyak mengandung unsur hara. Tomat juga merupakan tumbuhan dengan siklus hidup yang singkat, dapat tumbuh setinggi satu sampai tiga meter.

Ada beberapa ciri tomat diantaranya, tomat kategori buah yang pada umumnya berukuran lebih besar, dengan daging tebal, memiliki biji yang relatif sedikit dan berwarna merah. Tomat kategori sayur biasanya berukuran lebih kecil dari tomat buah dan yang lebih kecil lagi disebut tomat chery yang biasanya digunakan untuk hidangan bersama selada atau campuran membuat sambal. Sebagian orang berpendapat tomat adalah tanaman dalam golongan sayur sebagian lagi berpendapat tomat termasuk dalam golongan buah. Jika dilihat secara harfiah sayur dan buah ternyata tomat termasuk dalam golongan sayur dan buah sekaligus. Mengapa demikian? Penjelasaanya seperti ini buah didefinisikan sebagai produk tanaman yang mengandung biji dan dapat dimakan sekaligus sedangkan sayur dapat disebut bahan pangan yang berasal dari tumbuhan dan memiliki kandungan air yang tinggi. Dari penjelasan tersebut tomat memiliki keduanya, jadi kenapa tomat termasuk golongan sayur dan buah sekaligus.

Tingkat kematangan tomat dibagi menjadi tiga fase, yaitu fase masak hijau, fase pecah warna dan fase matang. Fase masak hijau ditandai dengan ujung buah tomat yang sudah mulai berwarna kuning gading. Pada fase pecah warna, ujung buah tomat menjadi berwarna merah jambu atau merah (Trisnawati dan Setiawan, 2002). Di negara maju, standart tingkat kematangan tomat dibuat lebih spesifik menjadi enam fase, yang meliputi : Green, Breakers, Turning, Pink, Light Red, dan Red (Florida Fruit \& Vegetables Association, 2005).

\section{Arduino UNO}

Arduino Uno merupakan papan mikrokontroler yang memiliki pin input dan output. Arduino Uno memiliki modul yang berguna untuk menunjang kinerja mikrokontroler, cukup dengan menghubungkan Arduino ke komputer hanya dengan kabel data USB atau mensuplai Arduino dengan adaptor DC atau menggunakan baterai untuk menjalankannya.

Untuk memprogram Arduino Uno dibutuhkan Arduino IDE, Arduino IDE adalah perangkat lunak yang digunakan untuk menulis atau membuat kode program yang akan di unggah ke dalam Arduino agar Arduino dapat berjalan sesuai dengan kode program yang dibuat dimana Arduino IDE ditulis dengan menggunakan Java.

\section{Sensor TCS3200}

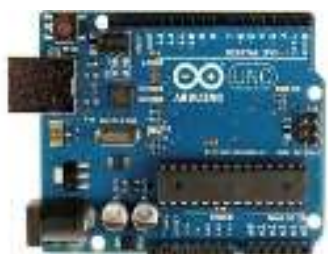

Gambar 1. Arduino Uno

Sensor TCS3200 merupakan IC yang mengkonversi warna cahaya ke suatu nilai atau sensor yang dipakai pada aplikasi mikrokontroler untuk pendeteksian warna suatu objek. Pada dasarnya pembacaan warna pada sensor ini dilakukan bertahap yaitu dengan membaca frekuensi warna dasar secara bersamaan dengan cara memfilter pada tiap - tiap warna dasar. Dengan begitu diperlukan sebuah logika untuk memfilter setiap warna tersebut.

Prinsip Kerja Sensor Warna TCS3200 bekerja dengan cara membaca nilai intensitas cahaya yang dipancarkan oleh LED super bright terhadap objek, pembacaan nilai intensitas cahaya tersebut dilakukan melalui matrik 8x8 photodioda, dimana 64 photo dioda tersebut dibagi menjadi 4 kelompok pembaca warna, setiap warna yang disinari LED akan memantulkan sinar LED menuju photodioda, pantulan sinar tersebut memiliki panjang gelombang yang berbeda - beda, tergantung pada warna objek yang terdeteksi. Hal berikut yang membuat sensor warna TCS3200 dapat membaca beberapa macam warna. 


\begin{tabular}{lll}
\hline S2 & S3 & Photodioda \\
\hline 0 & 0 & Merah \\
0 & 1 & Biru \\
1 & 0 & Clear (no filter) \\
1 & 0 & Hijau \\
\hline
\end{tabular}

Tabel 1. Fungsi Pin Sensor TCS3200

\begin{tabular}{lll}
\hline Nama & Kaki IC & Fungsi Pin \\
\hline S0,S1 & 1,2 & Saklar pemilih pada frekuensi output skala tinggi \\
OE & 3 & Output enable, sebagai input untuk frekuensi ouput skala rendah \\
GND & 4 & Ground pada power supply \\
Vdd & 5 & Supply tegangan \\
OUT & 6 & Output frekuensi \\
S2,S3 & 7,8 & Saklar pemilih 4 kelompok dioda \\
\hline
\end{tabular}

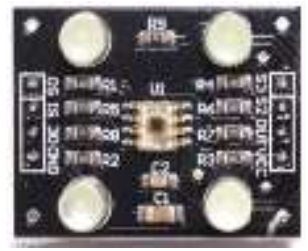

- Gambar 2. Sensor TCS3200

\section{Motor Servo}

Motor Servo merupakan perangkat yang menggunakan motor untuk melakukan putaran yang dirancang untuk sistem kontrol umpan balik loop tertutup, sehingga dapat diatur untuk menentukan posisi sudut yang diinginkan.

Motor servo berfungsi sebagai penggerak roda gigi agar dapat memutar potensiometer dan poros outputnya secara bersamaan. Potensiometer atau encoder berfungsi sebagai sensor yang akan memberikan sinyal umpan balik ke sistem kontrol untuk menentukan posisi targetnya. Jika sistem kontrol mendeteksi posisi target pada motor servo sudah benar, maka putarannya secara otomatis akan berhenti. Namun, jika posisi target atau sudutnya belum tepat maka motor servo akan diubah posisinya sampai benar.

\section{Motor DC}

Motor DC adalah alat untuk merubah energi listrik menjadi energi gerak dan dari energi gerak menjadi energi listrik. Motor DC dapat disebut sebagai motor arus searah, karena motor ini memiliki dua kutup dan memerlukan arus searah untuk dapat menjalankannya. Prinsip kerja Motor DC diantaranya terdapat dua bagian utama yaitu bagian yang berputar disebut Rotor, bagian Rotor ini terdiri dari kumparan kawat tembaga. Sedangkan bagian motor yang diam disebut Stator, bagian yang diam ini terdiri dari kerangka dan magnet permanen.

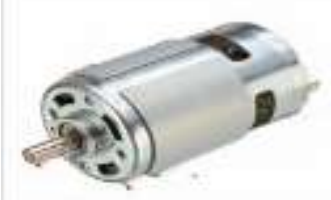

Gambar 3. Motor DC

\section{Sensor Ultrasonik}

Sensor ultrasonik merupakan sensor yang berguna untuk mengubah besaran suara menjadi besaran listrik dan sebaliknya. Cara kerjanya didasarkan pada pantulan gelombang suara ultrasonik sehingga 
dapat dijadikan acuan untuk menghitung jarak suatu benda dengan frekuensi tertentu. Sensor ini berfungsi sebagai pengirim atau trigger, penerima, dan pengontrol gelombang ultrasonik. Sensor ini difungsikan untuk menghitung jarak benda dari $2 \mathrm{~cm}$ hingga $4 \mathrm{~m}$ dengan tingkat akurasi $3 \mathrm{~mm}$.

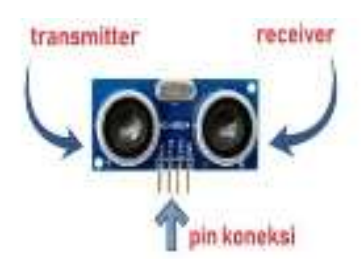

Gambar 4. Sensor Ultrasonik

\section{LCD (Liquid Crystal Display)}

LCD adalah satu dari sekian komponen elektronik yang berguna sebagai keluaran berupa tampilan suatu data, baik karakter, huruf, atau grafik. Karena banyaknya pin Input dan Output dari perangkat LCD 16 x 2, maka diperlukan sebuah modul tambahan yang dapat dipakai untuk menyederhanakan pin LCD 16 x 2 yaitu modul I2C. Dari 16 pin pada LCD 16 x 2, dapat disederhanakan menjadi 4 pin yaitu VCC, Ground, SDA dan SCL. Modul I2C membutuhkan tegangan sebesar 5V yang disuplai dari Arduino melalui pin VCC dan pin Ground. SDA (Serial Data) merupakan pin yang digunakan sebagai jalur pengiriman data. Sedangkan SCL (Serial Clock) merupakan pin yang digunakan sebagai jalur clock.

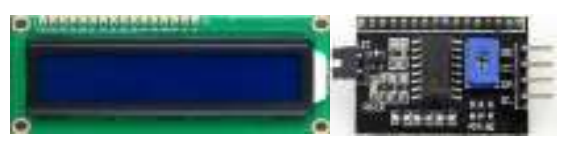

- Gambar 5. LCD (Liquid Crystal Display) dan Modul I2C

\section{Analisis Data}

\section{METODE PENELITIAN}

Analisis data bertujuan menjabarkan dan memecahkan suatu masalah berdasarkan data yang diperoleh. Analisis yang digunakan merupakan analisis data kualitatif. Analisis data kualitatif merupakan upaya yang dilakukan dengan cara mengumpulkan, memilih, mengklasifikasikan, dan merekam apa yang didapat dari sumber serta memberikan kode agar sumber dari data tersebut tetap dapat ditelusuri.

\section{Diagram Alir Pembuatan Alat}

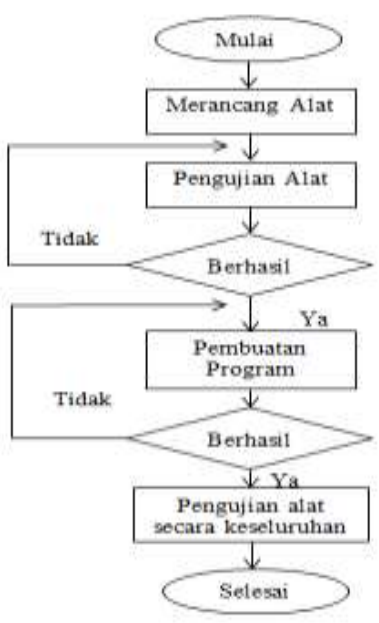

Gambar 6. Diagram Alir Pembuatan Alat

\section{Gambaran Umum Diagram Blok Rangkaian}

Gambaran umun cara kerja alat ini terdiri dari input yang berupa Sensor Warna TCS3200 dan Sensor Ultrasonik. Setelah input mendeteksi, data akan dikirim pada mikrokontroler Arduino Uno dan akan 
memberikan perintah output, dimana motor DC akan menggerakkan Servo pemilah utama yang berfungsi untuk penahan dan Servo pemilah tomat untuk memisahkan tomat berdasarkan warna yang selanjutnya akan menampilkan hasil dilayar LCD. Gambaran blok diagram rangkaiannya seperti di bawah ini :

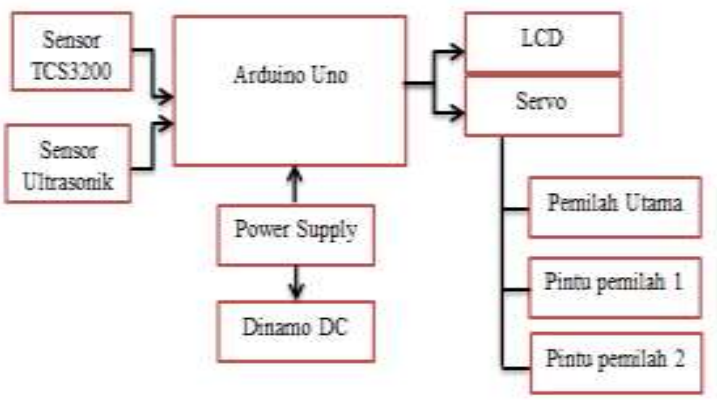

Gambar 7. Diagram Blok Rangkaian

\section{Desain Sistem Alat}

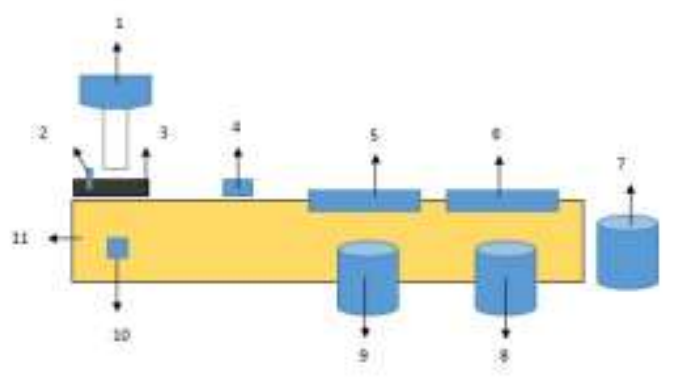

- Gambar 8. Desain Sistem Alat Pemisah Buah Tomat

Keterangan :

1. Wadah Penampung Tomat

2. Sensor Warna TCS3200

3. Pintu Pemilah Utama

4. Sensor Ultrasonik

5. Pintu Pemilah Buah Pertama

6. Pintu Pemilah Buah Kedua

7. Bak Pemilah Untuk Tomat Kuning

8. Bak Pemilah Untuk Tomat Hijau

9. Bak Pemilah Untuk Tomat Merah

10. Motor DC

11. Rak Conveyor 


\section{Diagram Alir Sistem}

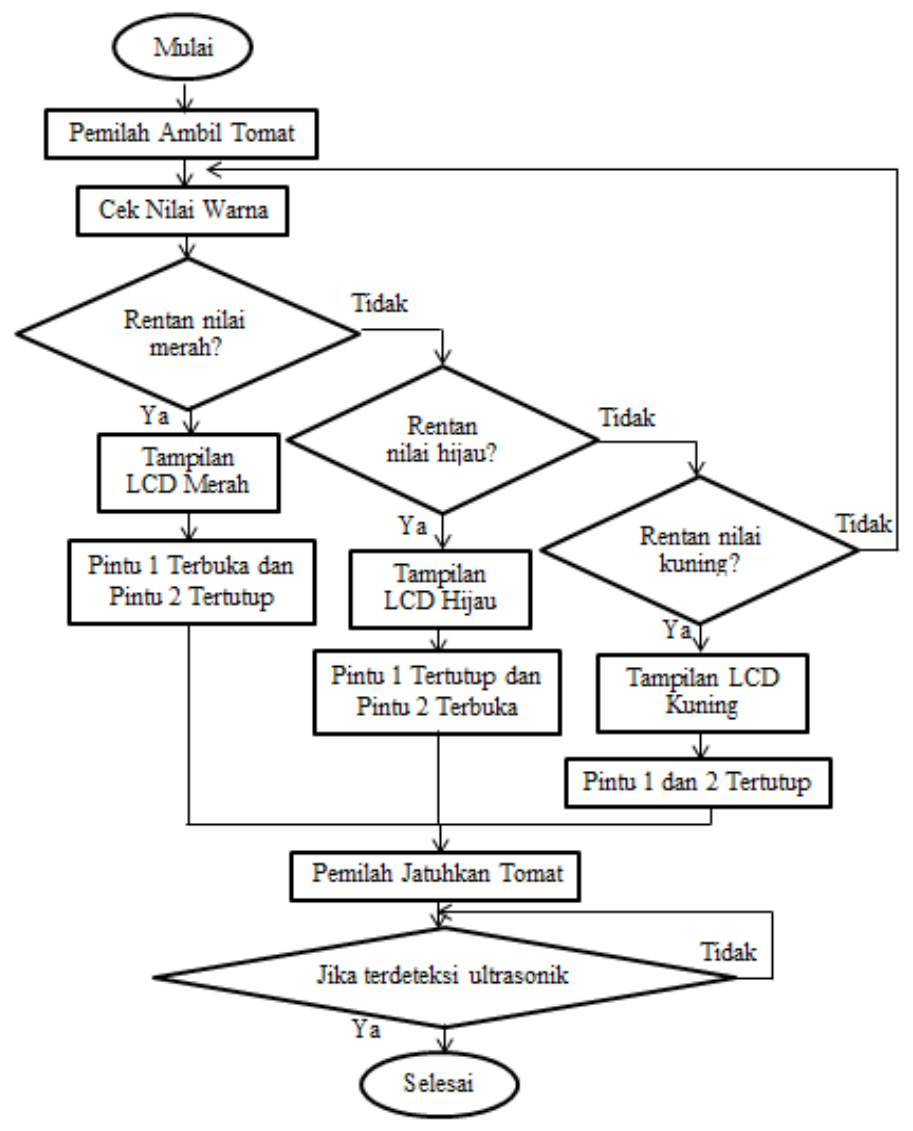

Gambar 9. Diagram Alir Sistem

\section{Rangkaian Sistem Sensor TCS3200}

\section{HASIL PENELITIAN}

Sensor TCS3200 berguna sebagai alat pendeteksi dengan cara mendeteksi dari segi warnanya untuk tomat yang matang berwarna merah, mentah berwarna hijau dan setengah matang berwarna kuning.

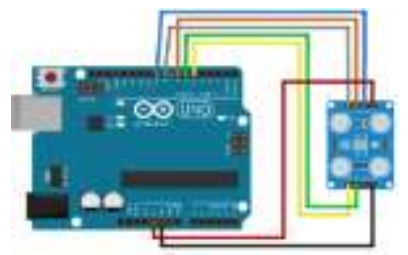

Gambar 10. Rangkain Sensor TCS3200 dengan Arduino Uno

- Tabel 2. Rangkaian Sensor TCS3200 ke Arduino Uno

\begin{tabular}{ll}
\hline Arduino Uno & TCS3200 \\
\hline Pin 5 & S0 \\
Pin 6 & S1 \\
Pin 7 & S2 \\
Pin 8 & S3 \\
Pin 9 & Out \\
5V & VCC \\
GND & GND \\
\hline
\end{tabular}

\section{Rangkaian Motor Servo}

Motor Servo adalah salah satu rangkaian motor arus tunggal dengan sistem umpan balik yang terdiri dari sebuah motor DC, serangkaian gir dan kontrol rangkaian. Motor servo dapat menampilkan gerakan 0 derajat, 90 derajat, 180 derajat, hingga 360 derajat. Fungsi beberapa motor servo ini sebagai pemilah utama untuk mengarahkan tomat ke conveyor dan sebagai pintu memilah tomat untuk 
dimasukkan kedalam wadah pemilah sesuai warnanya. Motor servo disini menggunakan motor servo standart dan motor servo rotation continous. Untuk motor servo standart digunakan untuk pintu pemilah buah sedangkan untuk motor servo rotation continous digunakan pada pintu pemilah utama.

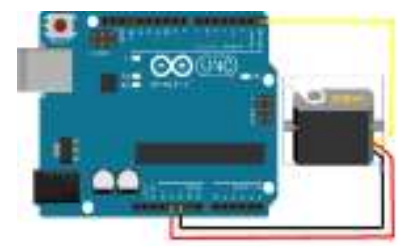

Gambar 11. Rangkaian Motor Servo dengan Arduino Uno

Tabel 3. Pin Servo ke Arduino

\begin{tabular}{cc}
\hline Arduino Uno & Servo \\
\hline GND & GND \\
$5 \mathrm{~V}$ & VCC \\
Pin 0 & Pulse \\
\hline
\end{tabular}

\section{Rangkaian Liquid Crystal Display (LCD) 16x2}

Banyaknya pin Input dan Output yang terdapat pada LCD 16x2 maka dibutuhkan sebuah modul yang dapat digunakan untuk menyederhanakan pin LCD 16x2 yaitu modul I2C. Dari 16 pin Input dan Output pada LCD 16x2 dapat disederhanakan menjadi empat pin yaitu VCC, GND, SDA dan SCL. Modul I2C memerlukan tegangan sebesar 5V yang disuplai dari Arduino melalui pin VCC dan pin GND sebagai grounding. SDA (Serial Data) adalah pin yang berguna sebagai jalur pengiriman data. Sedangkan SCL (Serial Clock) berguna sebagai jalur clock. Pada Arduino sudah tersedia pin SDA dan pin SCL, tidak seperti Arduino Uno yang belum tersedia. Namun sama seperti Arduino Uno yang memanfaatkan pin A4 dan A5 sebagai pin SDA dan SCL, pin A4 dan A5 Arduino juga digunakan sebagai pin SDA dan SCL.

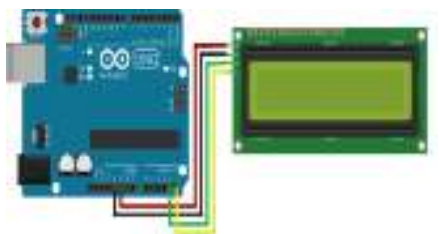

Gambar 12. Rangkaian LCD, I2C ke Arduino Uno

Tabel 4. Pin LCD dan I2C ke Arduino Uno

\begin{tabular}{cc}
\hline Arduino Uno & LCD dan Modul I2C \\
\hline A5 & SCL \\
A4 & SDA \\
VCC & 5V \\
GND & GND \\
\hline
\end{tabular}

\section{Rangkaian Motor DC}

Motor DC disebut juga sebagai Motor Arus Searah, karena mempunyai dua terminal dan membutuhkan tegangan arus searah untuk bisa menggerakannya. Motor DC ini berfungsi sebagai penggerak conveyor agar dapat berjalan memindahkan benda dari satu tempat ketempat lainnya. Untuk dapat menjalankan Motor DC tersebut diperlukan tambahan berupa sebuah catu daya yang dihubungkan ke aliran listrik.

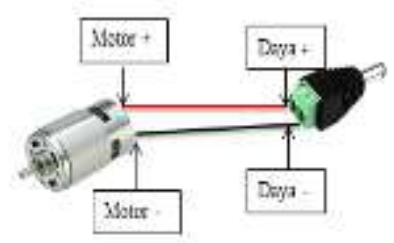

Gambar 13. Rangkaian Adaptor Dihubungkan dengan Motor DC 
- Tabel 5. Konfigurasi Motor DC dan Catu Daya

\begin{tabular}{cc}
\hline Adaptor & Motor DC \\
\hline Positif (+) & Positif (+) \\
Negatif (-) & Negatif (-) \\
\hline
\end{tabular}

\section{Rangkaian Sensor Ultrasonik}

Sensor Ultrasonik pada alat ini digunakan sebagai pembaca jarak yang berguna untuk mendeteksi pergerakan buah sudah melewati sensor ultrasonik untuk menuju pintu yang sudah ditentukan. Dan selanjutnya langkah alat dapat diulangi mulai dari awal lagi.

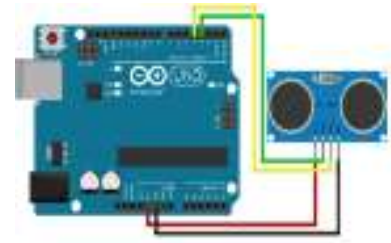

- Gambar 14. Rangkaian Ultrasonik dengan Arduino Uno

- Tabel 6. Pin Sensor Ultrasonik ke Arduino Uno

\begin{tabular}{ll}
\hline Arduino Uno & Sensor Ultrasonik \\
\hline VCC & VCC \\
GND & GND \\
Pin 3 & Trig \\
Pin 4 & Echo \\
\hline
\end{tabular}

\section{Gambar Rangkaian Keseluruhan}

Rangkaian keseluruhan sistem merupakan pengujian yang dilakukan setelah semua sistem terkonfigurasi. Konfigurasi tersebut sensor TCS 3200 sebagai sensor warna, Motor Servo sebagai pemilah utama dan penggerak pintu pintu pemilah buah, Sensor Ultrasonic sebagai pemberi sinyal saat buah tomat akan melewati pintu pemilah buah, LCD untuk menampilkan karakter atau tulisan warna buah dan Project Board sebagai penghubung agar semua komponen dapat terhubung dengan baik. Semua komponen tersebut terkonfigurasi dengan Arduino Uno dengan ditanamkan kode program untuk mengendalikan semua komponen tersebut.

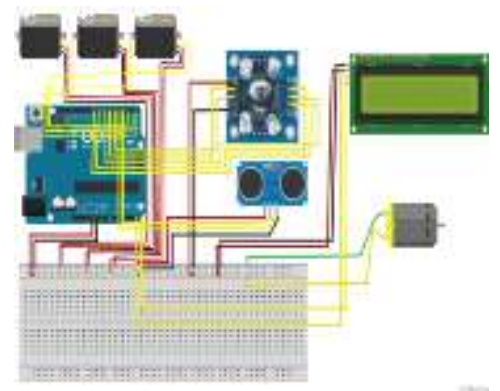

Gambar 15. Rangkaian Keseluruhan

\section{Conveyor}

Pada penelitian ini Conveyor digunakan untuk mengangkut buah tomat sehingga petani buah tomat tidak perlu lagi memindahkan tomat dari penampungan ke bak pemilahan secara manual.

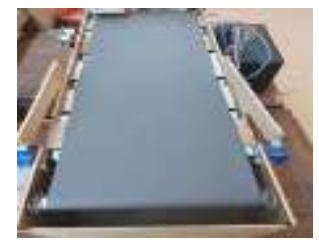

Gambar 16. Conveyor 


\section{Pintu Pemilah Utama (Motor Servo Utama)}

Pintu pemilah utama ini berguna sebagai pengambil tomat yang ada di penampungan, agar tomat dapat disortir satu persatu secara berurutan. Dan selanjutnya diletakkan diatas conveyor agar tomat dapat menuju pintu pemilah selanjutnya.

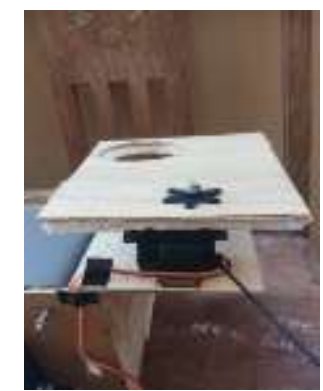

Gambar 17. Pintu Pemilah Utama

\section{Sensor TCS3200}

Sensor TCS3200 ini berguna sebagai sensor pendeteksi tomat sebelum buah tomat diletakkan diatas conveyor. Sensor ini dapat mendeteksi tomat tersebut berwarna merah, hijau, dan kuning. Setelah selesai dideteksi, LCD akan menampilkan hasil tomat tersebut.

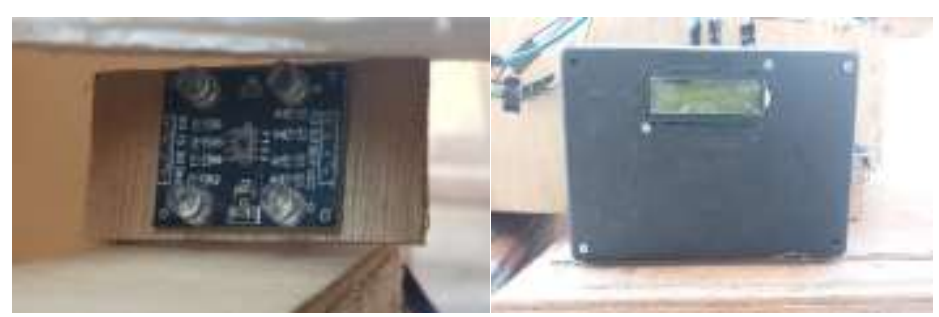

Gambar 18. Sensor TCS3200

\section{Pintu Pemilah Buah}

Pintu pemilah buah berguna sebagai pemilah buah tomat saat sensor TCS3200 telah mendeteksi warnanya, maka arduino uno akan mengirimkan sinyal ke motor servo sebagai penggerak pintu.

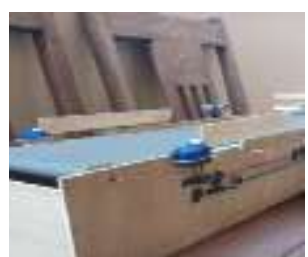

Gambar 19. Pintu Pemilah Buah

\section{Sensor Ultrasonik}

Ultrasonik disini berguna untuk mendeteksi pergerakan apabila buah tomat akan melewati pintu pemilah buah maka sensor ultrasonik akan mengirimkan sinyal kepintu pemilah utama agar mengulangi cara kerjanya. Cara kerja ini dimaksudkan agar buah dapat berjalan berurutan.

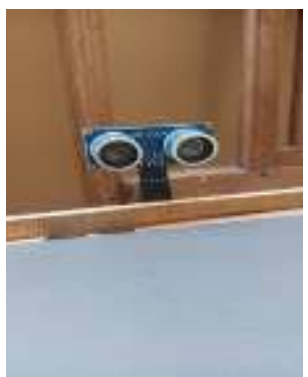

Gambar 20. Sensor Ultrasonik 


\section{Pengujian Sistem Pemilah Tomat Secara Keseluruhan}

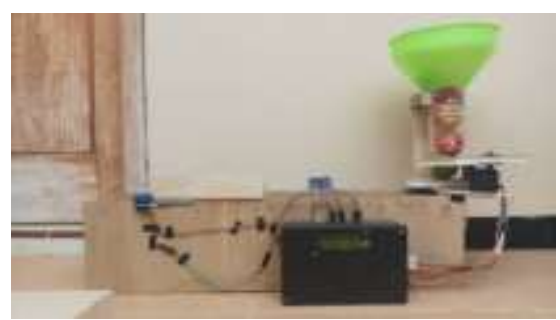

Gambar 21. Gambar Alat Keseluruhan

\section{Tomat Merah}

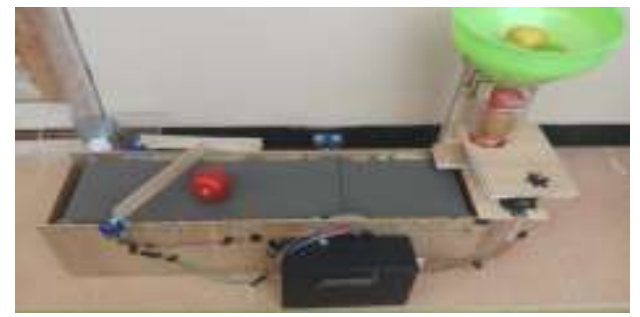

Gambar 22. Proses Pemilahan Tomat Merah

Pada gambar 22 proses dimana tomat sudah terdeteksi oleh sensor TCS3200 dan memperoleh hasil keterangan merah untuk selanjutnya masuk ke dalam pintu pemilah pertama.

\section{Tomat Hijau}

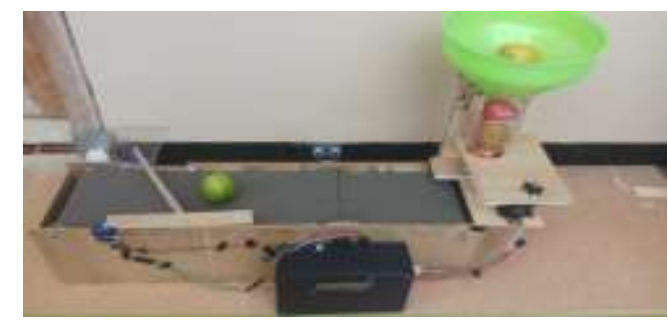

Gambar 23. Proses Pemilah Tomat Hijau

Pada gambar 23 proses dimana tomat sudah terdeteksi oleh sensor TCS3200 dan memperoleh hasil keterangan hijau untuk selanjutnya masuk kedalam pintu pemilah kedua.

\section{Tomat Kuning}

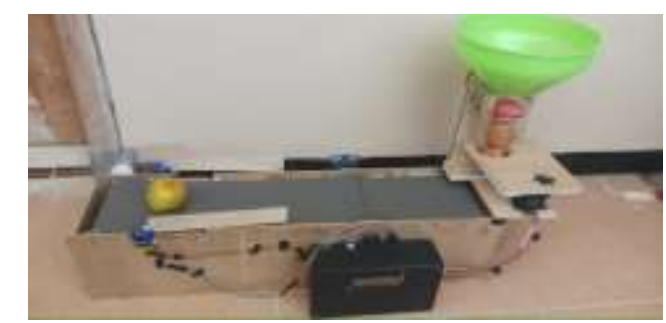

Gambar 24. Proses Pemilah Tomat Kuning

Pada gambar 24 proses dimana tomat sudah terdeteksi oleh sensor TCS3200 dan memperoleh hasil keterangan kuning untuk selanjutnya berjalan terus melewati pintu pemilah 1 dan pintu pemilah 2 .

\section{Proses Pembacaan Sensor TCS3200}

Proses saat sensor mendeteksi warna merah, hijau, kuning dan saat tidak ada warna (putih). Output dari sensor TCS3200 adalah gelombang kotak (duty cycle) dengan frekuensi yang berbanding lurus 
dengan intesitas cahaya (irradiance) yang mempunyai nilai minimal 0 dan maximum 750 . Penyesuaian skala dibutuhkan untuk mendapatkan nilai sesuai range warna RGB yang bernilai 0 hingga 255 . Metode yang diperlukan adalah metode mapping. Pengambilan sampel dilakukan dengan bantuan kertas berwarna. Hasil pembacaan warna dalam bentuk RGB akan muncul. Hasil dari pembacaan sensor ini kemudian dijadikan dasar dalam menentukan range warna.

Tabel 7. Proses Pembacaan Sensor TCS3200

\begin{tabular}{|c|c|c|c|c|c|c|c|c|c|c|c|}
\hline \multicolumn{3}{|c|}{ Putih } & \multicolumn{3}{|c|}{ Merah } & \multicolumn{3}{|c|}{ Hijau } & \multicolumn{3}{|c|}{ Kuning } \\
\hline $\mathrm{R}$ & $\mathrm{G}$ & B & $\mathrm{R}$ & G & B & $\mathrm{R}$ & $\mathrm{G}$ & B & $\mathrm{R}$ & $\mathrm{G}$ & B \\
\hline 30 & 43 & 41 & 72 & 35 & 38 & 90 & 111 & 54 & 113 & 103 & 34 \\
\hline 32 & 43 & 45 & 70 & 41 & 40 & 80 & 109 & 46 & 111 & 105 & 45 \\
\hline 37 & 49 & 50 & 69 & 32 & 30 & 96 & 110 & 62 & 107 & 96 & 50 \\
\hline 32 & 45 & 43 & 72 & 46 & 41 & 75 & 100 & 41 & 113 & 108 & 39 \\
\hline 34 & 45 & 47 & 68 & 45 & 40 & 80 & 107 & 57 & 109 & 98 & 41 \\
\hline
\end{tabular}

\section{Tabel Pengujian}

- Tabel 8. Data Hasil Pengujian Pada Alat Pemisah Buah Tomat

\begin{tabular}{|c|c|c|c|c|}
\hline No & Pengujian & Warna Tomat & Terdeteksi Sensor & Tingkat Keberhasilan \\
\hline 1 & Pengujian 1 & & Merah & Berhasil \\
\hline 2 & Pengujian 2 & & Hijau & Berhasil \\
\hline 3 & Pengujian 3 & & Merah & Gagal \\
\hline 4 & Pengujian 4 & & Hijau & Berhasil \\
\hline 5 & Pengujian 5 & & Kuning & Gagal \\
\hline 6 & Pengujian 6 & & Merah & Gagal \\
\hline 7 & Pengujian 7 & & Hijau & Berhasil \\
\hline 8 & Pengujian 8 & & Hijau & Berhasil \\
\hline 9 & Pengujian 9 & & Merah & Berhasil \\
\hline 10 & Pengujian 10 & & Kuning & Berhasil \\
\hline \multicolumn{2}{|c|}{ Total Percobaan } & 10 & Total Berhasil & 7 \\
\hline
\end{tabular}

Berdasarkan table 8 diatas, maka didapatkan perhitungan akurasi sensor TCS3200. Berikut ini merupakan perhitungan akurasi sensor TCS3200:

$$
\begin{aligned}
\text { Persentase error } & =\frac{\text { Niai error }}{\text { Percobaan }} \times 100 \% \\
& =\frac{(10-7)}{10} \times 100 \% \\
& =30 \% \\
\text { Akurasi Sensor } & =100 \%-30 \% \\
& =70 \%
\end{aligned}
$$


Berdasarkan perhitungan akurasi sensor TCS3200 sesuai dengan tabel pengujian yang dilakukan terhadap warna buah tomat maka diperoleh nilai akurasi sensor TCS3200 yaitu 70\%.

\section{Kesimpulan}

\section{KESIMPULAN DAN SARAN}

Berdasarkan hasil dari penelitian yang dilakukan, maka dapat diambil kesimpulan sebagai berikut :

1. Sensor warna TCS3200 berguna sebagai pendeteksi warna untuk mendapatkan nilai RGB dari buah tomat.

2. Proses merancang alat pemisah buah tomat otomatis berdasarkan warna menggunakan sensor TCS3200 berbasis Arduino UNO melalui perancangan skema rangkaian, pemilihan alat dan komponen yang digunakan hingga alat bisa bekerja dengan baik.

3. Telah terealisasi alat pemisah buah tomat yang meliputi pembacaan RGB oleh sensor TCS3200 dengan tingkat kegaglan sebesar 30\%.

4. Kesalahan pada pendeteksian warna tomat untuk alat sortir ini dipengaruhi dengan pembacaan nilai RGB oleh sensor TCS3200 yang sensitif terhadap perubahan intesitas cahaya.

5. Dengan menggunakan alat ini pekerja dapat meminimalisir waktu yang terbuang terlalu banyak.

\section{Saran}

Dalam penelitian ini tidak lepas dari kekurangan dan kelemahan, untuk itu pengembangan alat lebih lanjut diperlukan perhatian terhadap beberapa hal, diantaranya :

1. Pengembangan selanjutnya tentang Rancang Bangun Alat Pemisah Buah Tomat Berdasarkan Warna Menggunakan Arduino dan Sensor Cahaya dapat dibuat lebih besar supaya dapat memuat kapasitas buah lebih banyak lagi.

2. Pengembangan selanjutnya bisa ditambah menggunakan sensor berat, agar dalam pemilahan bisa membedakan tomat berukuran kecil dan berukuran besar. Sehingga nantinya dapat lebih rapi saat pengemasan tomat yang siap untuk dijual.

3. Komponen motor AC sebaiknya bisa diganti dengan torsi yang lebih besar agar lebih mudah untuk menggerakkan beberapa piring

4. Untuk ruangan pengering sebaiknya segala sisinya ditutup rapat dengan bahan yang lebih keras, sehingga udara panas yang dihasilkan oleh heater dapat menyebar dengan cepat, agar proses pengeringan piring ini lebih mudah, efektif dan efisien.

5. Dalam pengembangan selanjutnya diharapkan dapat menjalankan tidak hanya 1 piring, namun beberapa piring dan proses dapat dilakukan secara terus-menerus.

\section{DAFTAR PUSTAKA}

[1] Amin, Mohammad Fauzin, Sabriansyah Rizkiqa Akbar, dan Edita Rosana Widasari, "Rancang Bangun Sistem Sortir Buah Apel Menggunakan Sensor Warna dan Sensor Suhu”, Program Studi Teknik Infromatika, Fakultas Ilmu Komputer, Universitas Brawijaya, Malang, ISSN 2548-964X, Vol. 1 No.3, Maret 2017.

[2] Ariadana, Lb Novendita, Dahnial Syauqy, dan Tibyani, "Rancang Bangun Sistem Pemilah Tomat Berdasarkan Tingkat Kematangan" Program Studi Teknik Informatika, Fakultas Ilmu Komputer, Universitas Brawijaya, Malang, ISSN 2548-964X, Vol. 3 No. 2, Februari 2019.

[3] Darminta, I Ketut, I Nyoman Sukarma, dan I Made Budiawan, "Simulasi Pemisah Kematangan Buah Jeruk Berdasarkan Warna Berbasis Mikrokontroler Atmega 382P”, Fakultas Teknik Elektro, Politeknik Negeri Bali, Juli 2017.

[4] Hasanah, A., dan Marlina, "Pengaruh Inokulasi Mikoriza Vesikula Arbuskula (MVA) Campuran Terhadap Kemunculan Penyakit Layu Fusarium Pada Tanaman Tomat (Solanum Lycopersicum)", Universitas Jendral Soedirman, Purwokerto, Maret 2017.

[5] Hidayat, Darmawan, Bambang Mukti Wibawa, Setianto, Nendi Suhendi Syafei dan Arif Choerudin Suanda, "Sistem Sensor Estimasi Tingkat Kamatangan Buah Stroberi Berdasarkan Kecerahan Warna Merah", Departemen Teknik Elektro dan Departemen Fisika, Fakultas MIPA, Universitas Padjadjaran, Jawa Barat, ISSN 2548-8678, Vol. 2 No.2, Desember 2017.

[6] Listiana, "Pengaruh Medan Magnet 0,2 Mt Terhadap Pertumbuhan Generatif Tanaman Tomat (Lycopersicum Esculentum Mill) yang Diinfeksi Fusarium Oxysporum”, Universitas Lampung, Bandar Lampung, 2016. 
[7] Sabahannur, St dan Lingga Herawati, "Pertumbuhan dan Produksi Tanaman Tomat (Licoprsicon Esculentum Mill) Pada Berbagai Jarak Tanam dan Pemangkasan", Fakultas Pertanian, Universitas Muslim Indonesia, Makassar, 2017. 